\title{
Solid-Contact Ion-Selective Electrodes Based on Graphite Paste for Potentiometric Nitrate and Ammonium Determinations
}

\author{
Johannes Schwarz ${ }^{1 *}$, Kathrin Trommer ${ }^{1}$, Michael Mertig1,2 \\ ${ }^{1}$ Kurt-Schwabe-Institut für Mess- und Sensortechnik e.V. Meinsberg, Waldheim, Germany \\ ${ }^{2}$ Technische Universität Dresden, Dresden, Germany \\ Email: *johannes.schwarz@ksi-meinsberg.de
}

How to cite this paper: Schwarz, J., Trommer, K. and Mertig, M. (2018) Solid-Contact Ion-Selective Electrodes Based on Graphite Paste for Potentiometric Nitrate and Ammonium Determinations. American Journal of Analytical Chemistry, 9, 591-601.

https://doi.org/10.4236/ajac.2018.912043

Received: October 16, 2018

Accepted: December 1, 2018

Published: December 4, 2018

Copyright $\odot 2018$ by author(s) and Scientific Research Publishing Inc. This work is licensed under the Creative Commons Attribution International License (CC BY 4.0).

http://creativecommons.org/licenses/by/4.0/

(c) (i) Open Access

\begin{abstract}
Robust and easy-to-handle solid-contact ion-selective electrodes (SC-ISEs) based on graphite paste have been developed for the potentiometric detection of $\mathrm{NO}_{3}^{-}$and $\mathrm{NH}_{4}^{+}$in environmental samples. Polypyrrole (PPy) has been used as intermediate layer and solid contact between the electron-conducting graphite paste substrate and the ion-conducting polyvinylchloride (PVC)-containing membrane with the immobilized ionophore. For the nitrate- and ammonium-selective electrodes, tridodecylmethylammonium nitrate (TDMA- $\mathrm{NO}_{3}$ ) and nonactin have been used as ion-complexing compounds, respectively. Both ISEs show nearly Nernstian response in the linear range from $10^{-5} \mathrm{~mol} / \mathrm{L}$ to $10^{-1} \mathrm{~mol} / \mathrm{L}$ with average slopes of $>58 \mathrm{mV} /$ decade. The ISEs possess short response times $(<20 \mathrm{~s})$.
\end{abstract}

\section{Keywords}

Solid-Contact Electrode, Graphite Paste, All-Solid-State Configuration, Ion-Complexing Compound, Environmental Samples

\section{Introduction}

Nitrate contamination is one of the most ubiquitous drinking water pollutants worldwide and is causing serious environmental problems. Intensive agricultural activities cause an increase of nitrate concentration in surface and groundwater. Nitrates are widely used in explosives, fertilizers and many industrial products. Agriculture and sewage effluents as well as other environmental samples contain high concentrations of nitrate. Nitrate is easily washed out from soil leading to high contaminations in drinking water samples. Groundwater and well water in 
some regions of Germany are highly contaminated by nitrates due to decaying plants and animal materials, agricultural fertilizer and domestic sewage. Highly contaminated ground- and well water by nitrate cannot be used as drinking water due to hazard to human health. These samples can only be cleaned with high technical and financial efforts to maintain the legally required limiting values.

Nitrate is degraded to toxic nitrite, which can cause methemoglobinemia, and to cancerogenic $\mathrm{N}$-nitrosamines, presenting a great danger for human health. Beside nitrate, ammonium concentration is increasing in the environment as a result of discharge from wastewater treatment plants, industrial effluents and agriculture runoffs. Ammonium, besides nitrate, is another important component of nitrogenous fertilizers. It is toxic to aquatic life due to its reduction to nitrate by oxygen and certain bacteria. High ammonium contents promote algae growth. Therefore, due to their widespread applications and common occurrence, nitrate and ammonium constitute important environmental parameters to access water quality in many environmental samples. Or in other words, nitrate and ammonium concentration levels are important pollution control parameters. Contamination by nitrate and ammonium in ground- and surface water has been steadily increasing during the last years. Contamination of both ions is still high in many regions of Germany due to intensive agricultural activities [1] [2] [3].

The presence of both ions in natural water can be associated in most cases to pollution caused by livestock, intense agriculture and domestic sewage. They indicate the eutrophication degree. High concentration of both pollutants encumbers ecological balance of natural waters and quality of drinking water.

Measurement of nitrate and ammonium content is, therefore, of great importance to get information of the ecosystem balance. Monitoring and surveillance of these ions in the field in agricultural areas is often required. A continuous and preventative analysis is, therefore, of great importance in view of limiting values and immediate reaction on incidents, too.

The current WHO drinking water guideline permits $50 \mathrm{mg}$ of nitrate per liter. The European Community (EU) requires a limiting value of $50 \mathrm{mg} / \mathrm{L}(\mathrm{ppm})$ of nitrate, too

In some regions of Germany this value is often exceeded. According to the German Drinking Water Act, the limiting value for ammonium is $0.5 \mathrm{mg} / \mathrm{L}$ [4].

Graphite paste electrodes consisting of a mixture of graphite powder and organic binder found widespread applications in electrochemical analysis. Graphite is a nontoxic and environmentally friendly electrode material, and is used in voltammetry as well as in potentiometry [5] [6].

Solid-contact ion-selective electrodes (SC-ISEs) offer several advantages over conventional electrodes with internal electrolytes, like small size, simple design and low cost. As solid contact material and as intermediate layer between the ion-selective membrane and the graphite, polypyrrole has been used. It offers a definite transfer of ion to electrical charge. SC-ISEs without any internal electrolytes present promising low-cost analytical tools due to their advantages, such as 
miniaturization, portability, fast response, simplicity in operation and low production cost, for widespread application fields. No internal electrolyte solution needs to be incorporated. They offer, therefore, excellent opportunities for remote monitoring and rapid mobile field-analysis, and thus, have found widespread practical applicability. Solid-contact ion-selective electrodes are suitable as simple on-site disposable analyzers, combine ease of use with simple, inexpensive accessible manufacturing techniques, and need simple instrumentation only. As solid contacts, conducting polymers are commonly used [7] [8] [9] [10].

So far, nitrate and ammonium determinations were mainly carried out using laboratory-based instrumental analysis methods, such as ion chromatography and spectroscopy methods. These methods require in general expensive equipment and complicated operation procedures, samples pretreatment, use of chemicals and qualified personal. They are time consuming and are not suitable for field analysis and mobile in-situ measurements.

Low-cost and easy-to-handle chemical analyzers, usable infields, are of increasing interest in environmental analysis. Electrochemical sensors are well suited for on-line analysis due to their sensitivity and portability. During the last years, there has been an increasing demand and high public interest for miniaturized, analytical devices for on-site and in-situ determination of environmental pollutants. It is, therefore, of great interest to transfer analytical measurements from the laboratory to the field.

Commercially, in most cases ion-selective electrodes for potentiometric nitrate and ammonium determinations are based on inner liquid electrolytes. Moreover, a quaternary ammonium salt is trapped in a PVC membrane. Most of them are in macroscopic form. Therefore, they are both difficult to handle and to miniaturize for field applications. Ion-complexing compounds are described in literature, but they have to be synthesized in complicated manner. These compounds did not found application in commercially available until today. Synthesis of new ion-complexing compounds for both ions is difficult to realize and requires long preparation procedures [11] [12] [13] [14].

The aim of this work was the development of inexpensive, simple, robust and fit-for-the-field solid-contact all-solid-state (ASS) ISEs based on graphite paste for potentiometric detection of nitrate and ammonium in environmental samples.

\section{Experimental}

\subsection{Reagents and Solutions}

All chemicals used were of analytical or selectophore grade and used as received without further purification. Standard solutions were prepared from $\mathrm{NH}_{4} \mathrm{NO}_{3}$. All solutions were prepared using deionized water. Working solutions were obtained by dilution of stock solutions. The following components for membrane preparation are purchased from Sigma-Aldrich. As ion-selective components have been used nonactine and TDMA- $\mathrm{NO}_{3}$. As plasticizers, bis(1-butylpentyl)adipate 
and dibutyl phthalate were used. Also poly(vinyl)chloride, tetrahydrofurane (THF), pyrrole and salt solutions containing nitrate and ammonium ions have been used.

As eluent for chromatographic anion detection $\mathrm{Na}_{2} \mathrm{CO}_{3}(3.6 \mathrm{mmol} / \mathrm{L})$ has been used.

\subsection{Apparatus}

Potentiometric measurements were carried out at room temperature $\left(20^{\circ} \mathrm{C} \mathrm{-}\right.$ $22^{\circ} \mathrm{C}$ ) using a $\mathrm{pH} /$ ion analyzer (WTW, Germany; LM 2000, Sensortechnik Meinsberg, Germany). Ag/AgCl reference electrodes (Kurt-Schwabe-Institute Meinsberg, Germany) with saturated $\mathrm{KCl}$ as electrolyte have been used. Reference analyses were carried out with an ion chromatography system (Metrohm 850 Professional) with a Metrosep A Supp 7 - 250 column (Metrohm).

\section{Electrode Construction and Preparation}

Graphite paste is produced by mixing graphite powder with epoxy resin and hardener. The paste was filled into a plastic holder. A copper wire as electrical connection was put into the paste.

A mediator layer of polypyrrole was applied on the graphite paste, and then the ion-selective membrane was dropped on the conducting polymer. Both polymeric layers adhere well on the graphite resp. conducting layer. Deposition of PPy was carried out in a monomer solution containing $0.1 \mathrm{~mol} / \mathrm{L}$ pyrrole and 0.1 mol/L potassium chloride or potassium nitrate to yield a conducting polymer layer doped with chloride anions and potassium cations.

The deposition of PPy has been realized via in-situ electropolymerization by direct deposition onto the surface of graphite. Applying cyclic voltammetry, PPy films are deposited by repetitive cycling within the potential range from $+0.2 \mathrm{~V}$ to $+0.7 \mathrm{~V}$ vs. $\mathrm{Ag} / \mathrm{AgCl}$ at a scan rate of $10 \mathrm{mV} / \mathrm{s}$ for 100 cycles. The thicknesses of the PPy films yield between $5-8 \mu \mathrm{m}$. After the deposition of the conducting polymer, the ion-selective cocktails were drop casted by pipetting 5 - $10 \mu$ onto the conducting polymer film. The solvent was allowed to evaporate. Preparation of the ion-selective electrodes has been carried out by following steps:

- Graphite paste (layer 1),

- Depletion of PPy on graphite transducer (layer 2),

- Depletion of ion-selective membrane on conducting polymer (layer 3 ).

Figure 1 shows the schematic structure of a graphite paste based ion selective electrode. In Figure 2 novel carbon-paste ion-selective electrodes are shown.

The ion-selective membrane composition has been optimized by varying the weight composition of the single membrane components. In Table 1 the optimized membrane compositions are summarized. Weight percent of the single components are given in brackets.

Figure 3 shows the ion-complexing compounds which have been incorporated in PVC-membranes. 


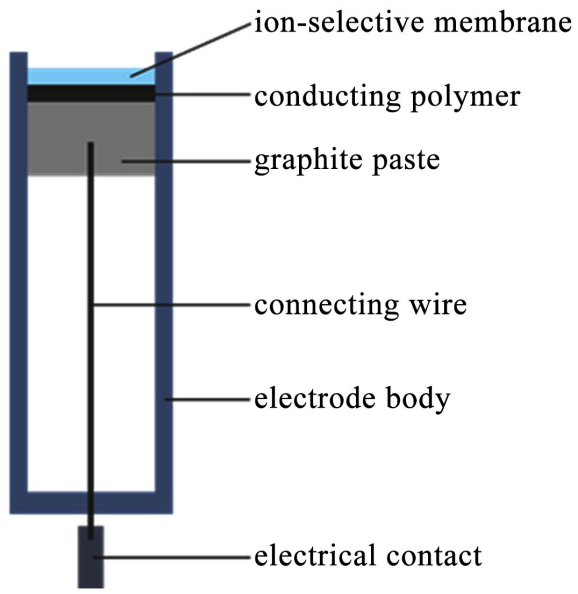

Figure 1. Schematic structure of the ion-selective electrode based on graphite paste.

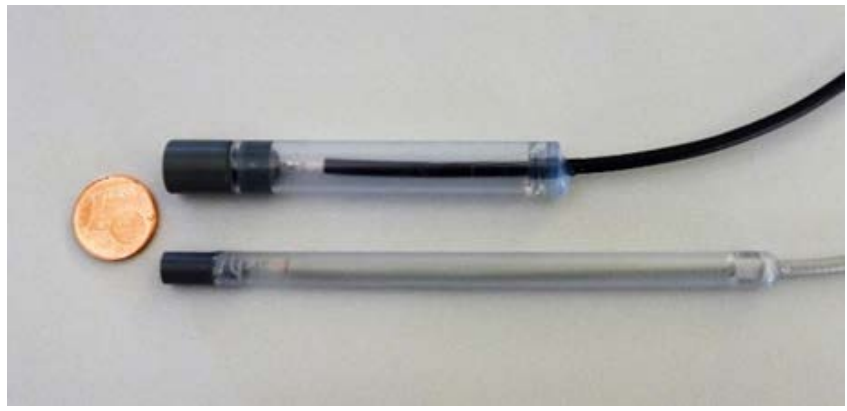

Figure 2. Graphite paste ion-selective electrodes of different dimensions.

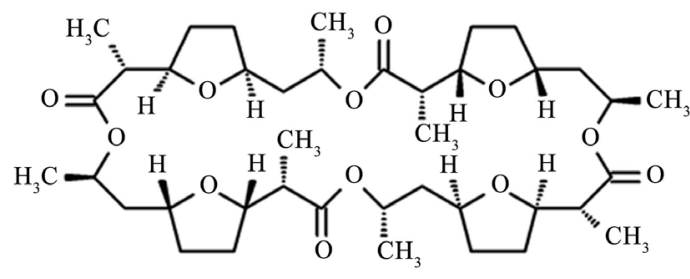

(a)

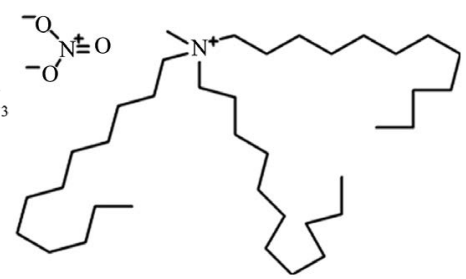

(b)

Figure 3. Ion-complexing compounds: (a) $\mathrm{NH}_{4}^{+}$complexing substance (nonactin); (b) $\mathrm{NO}_{3}^{-}$ionophore (TDMA- $\mathrm{NO}_{3}$ ).

Table 1. Membrane composition.

\begin{tabular}{|c|c|c|}
\hline Component & $\mathrm{NH}_{4}^{+}$-selective electrode & $\mathrm{NO}_{3}^{-}$-selective electrode \\
\hline Ionophore & $\begin{array}{l}\text { Nonactin } \\
{[1.0 \mathrm{wt} \%]}\end{array}$ & $\begin{array}{c}\text { Tridodecylmethylammonium nitrate } \\
\left(\text { TDMA- } \mathrm{NO}_{3}\right) \\
{[7.1 \mathrm{wt} \%]}\end{array}$ \\
\hline Plasticizer & $\begin{array}{c}\text { Bis(1-butylpentyl) adipate } \\
\text { [66.8 wt\%] }\end{array}$ & \\
\hline Polymer & $\begin{array}{l}\text { Poly(vinyl) chloride } \\
\text { [32.2 wt\%] }\end{array}$ & $\begin{array}{c}\text { Poly(vinyl) chloride } \\
\text { [28.6 wt\%] }\end{array}$ \\
\hline
\end{tabular}




\section{Results and Discussion}

\subsection{Potentiometric Investigations}

The ion-selective electrodes were conditioned in $10^{-2} \mathrm{~mol} / \mathrm{L}$ of standard solution for 5 hours before the first measurement. Performance and characteristic values of the electrodes were determined.

Figure 4 und Figure 5 show the response behavior of the $\mathrm{NH}_{4}^{+}$- and $\mathrm{NO}_{3}^{-}$selective ASS electrodes in standard solutions. The ISEs show linear potentiometric response towards the ions in the range $10^{-5} \mathrm{~mol} / \mathrm{L}-1 \mathrm{~mol} / \mathrm{L}$ and stable potentials.

Characteristic electrochemical electrode parameters are given in Table 2.
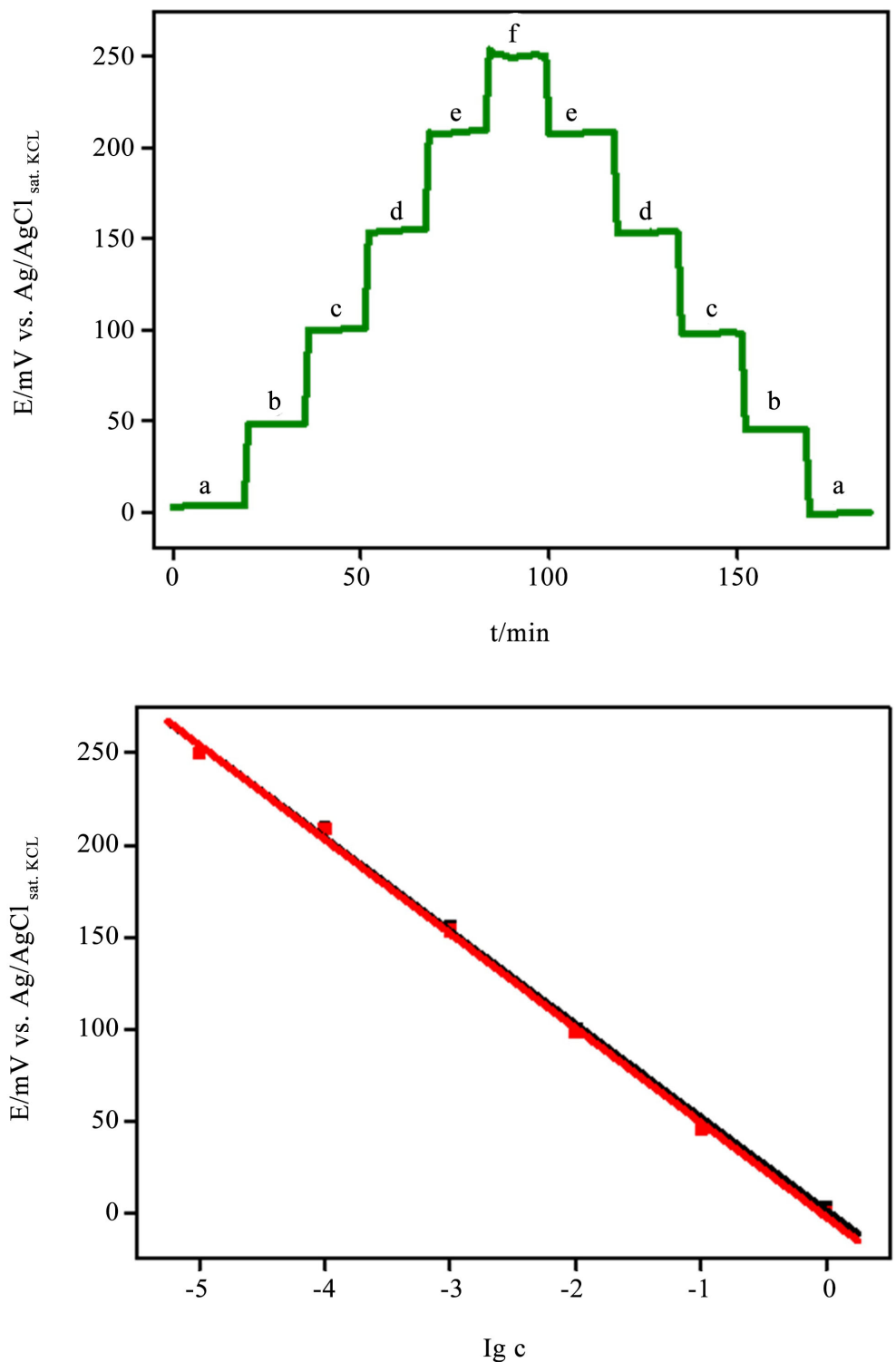

Figure 4. Potentiometric response behavior and calibration plot of a $\mathrm{NO}_{3}^{-}$ -selective ASS electrode; standard solutions of $\mathrm{NH}_{4} \mathrm{NO}_{3}$ : a. $1 \mathrm{~mol} / \mathrm{L}$, b. $10^{-1}$ $\mathrm{mol} / \mathrm{L}$, c. $10^{-2} \mathrm{~mol} / \mathrm{L}, \mathrm{d} .10^{-3} \mathrm{~mol} / \mathrm{L}$, e. $10^{-4} \mathrm{~mol} / \mathrm{L}, \mathrm{f} .10^{-5} \mathrm{~mol} / \mathrm{L}$. 

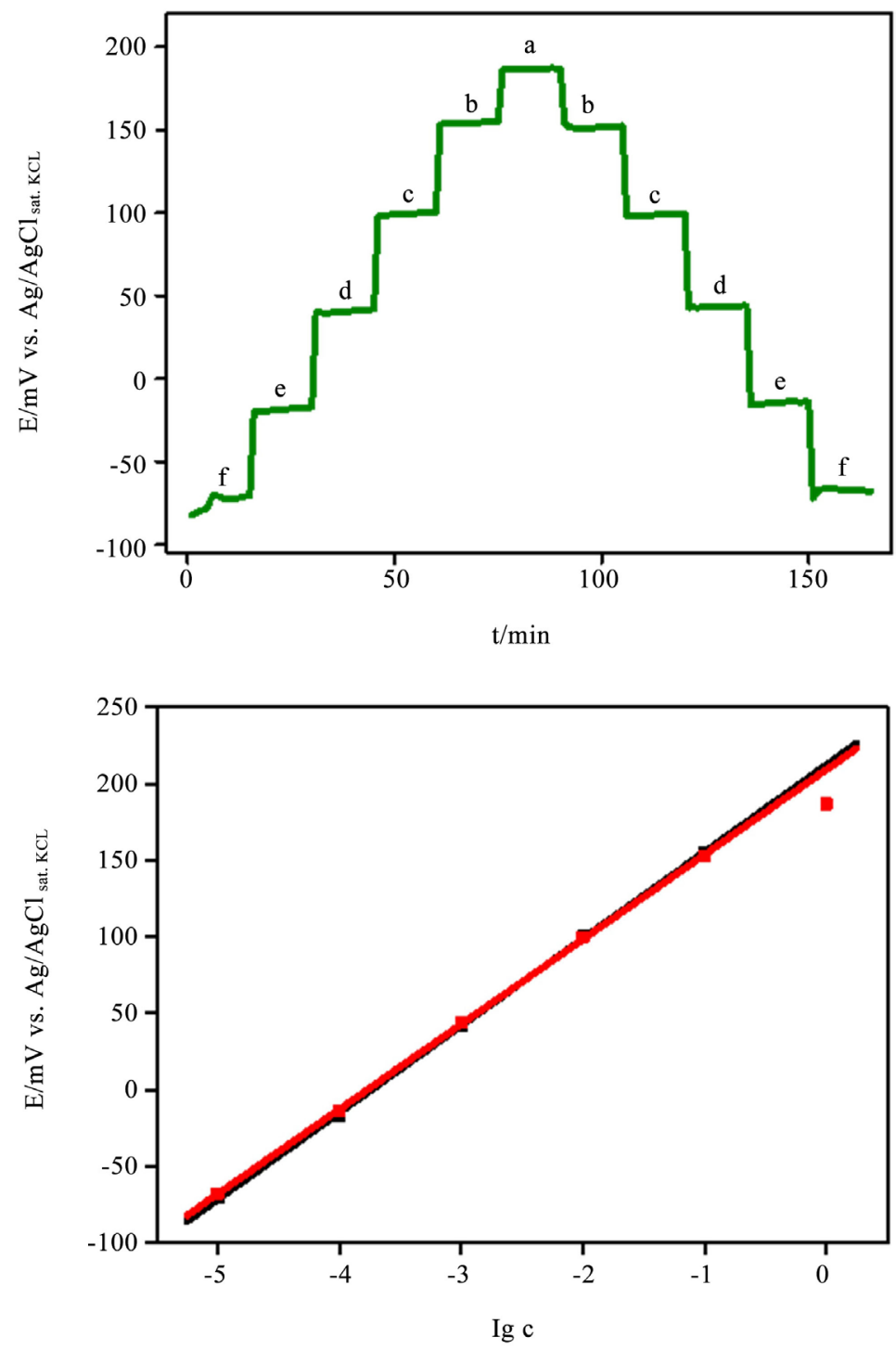

Figure 5. Potentiometric response behavior and calibration plot of a $\mathrm{NH}_{4}^{+}$-selective ASS electrode; standard solutions of $\mathrm{NH}_{4} \mathrm{NO}_{3}$ : a. $1 \mathrm{~mol} / \mathrm{L}$, b. $10^{-1} \mathrm{~mol} / \mathrm{L}$, c. $10^{-2} \mathrm{~mol} / \mathrm{L}$, d. $10^{-3} \mathrm{~mol} / \mathrm{L}$, e. $10^{-4} \mathrm{~mol} / \mathrm{L}$, f. $10^{-5} \mathrm{~mol} / \mathrm{L}$.

Table 2. Electrode characteristics.

\begin{tabular}{ccc}
\hline Parameter & $\mathrm{NH}_{4}^{+}$-ISE & $\mathrm{NO}_{3}^{-}$-ISE \\
\hline $\begin{array}{c}\text { Sensitivity }[\mathrm{mV} / \text { decade in range of } \\
\text { mol/L to } 10^{-5} \text { mol/L] }\end{array}$ & $>52$ & $>-52$ \\
Coefficient of determination $\left[\mathrm{R}^{2}\right]$ & 0.991 & 0.995 \\
Limit of detection [mol/L] & $<10^{-6}$ & $<-10^{-5}$ \\
$\begin{array}{c}\text { Selectivity coefficient }\left[\mathrm{lg} k^{\mathrm{pot}}\right] \\
\text { (main interfering ion) } \\
\text { Response time [s] }\end{array}$ & $\mathrm{K}^{+}:-0.85$ & $\mathrm{Cl}^{-}:-1.63$ \\
Life time [month] & $<25$ & $<25$ \\
Linear range [mol/L] & $6-12$ & $6-12$ \\
& $10^{-1}-10^{-6}$ & $10^{-1}-10^{-5}$ \\
\hline
\end{tabular}


The relative standard deviation (RSD) for the nitrate and ammonium electrodes in the range of $10^{-3}-10^{-5} \mathrm{~mol} / \mathrm{L}$ was below $4 \%(\mathrm{n}=5)$ for both ions. The electrodes are applicable in the $\mathrm{pH}$ range of $3-8$, where the potential remained constant. Selectivity is of great importance, as it determines the extent of utility of the ISE in real sample measurements. Selectivity coefficients show the potential interference of other ions on the potential response of the ISEs. The selectivity coefficients were determined by applying the fixed interference method (FIM) and separate solution method (SSM). Concentration of the interfering ion was $10^{-2} \mathrm{~mol} / \mathrm{L}$. Response time, slope of calibration curve, detection limit and selectivity coefficients of main interfering ions are presented. Life times of the electrodes under laboratory conditions is more than 3 years. After 2 years both electrodes still show slopes of $>90 \%$ compared to initial values.

\subsection{Applications}

Different tap water and well water samples from Germany have been analyzed by direct potentiometry using the novel ion-selective ASS electrodes. No sample preparation has been carried out. In Figure 6, the potentiometric response is shown in standard solutions and real samples.

The determined nitrate concentrations have been compared with results achieved by ion chromatography as reference method. Table 3 gives obtained results by both methods from different German tap and well water samples. Good agreement between both methods has been achieved. The nitrate concentrations in the determined tap water samples are below the limiting value of 50 $\mathrm{mg} / \mathrm{L}$ for drinking water, whereas the well water samples show higher nitrate concentration, and therefore, cannot be used as drinking water sources.

In Figure 7 a calibration plot for a $\mathrm{NH}_{4}^{+}$-selective electrode is shown. A tap water sample (Hartha Germany) has been analyzed by direct potentiometry with the new ISEs. A $\mathrm{NH}_{4}^{+}$-amount of $0.18 \mathrm{mg} / \mathrm{L}$ have been evaluated. The limiting value $(0.5 \mathrm{mg} / \mathrm{L})$ according to the German Drinking Water Act (Deutsche Trinkwasserverordnung) is marked. The $\mathrm{NH}_{4}^{+}$-concentration in the sample is below this limiting value.

Table 3. Nitrate content of real water samples by different methods.

\begin{tabular}{ccc}
\hline Real sample & $\begin{array}{c}\text { Ion-selective electrodes } \\
{[\mathrm{mg} / \mathrm{L}]}\end{array}$ & $\begin{array}{c}\text { Ion chromatography } \\
{[\mathrm{mg} / \mathrm{L}]}\end{array}$ \\
\hline Freiberg (tap water) & 22 & 22 \\
Enkenbach (tap water) & 33 & 31 \\
Köln (tap water) & 17 & 16 \\
Leisnig (tap water) & 8 & 7 \\
Hartha (tap water) & 27 & 30 \\
Döbeln (tap water) & 25 & 23 \\
Miera (well water) & 87 & 83 \\
Hermsdorf (well water) & 79 & 79 \\
\hline
\end{tabular}



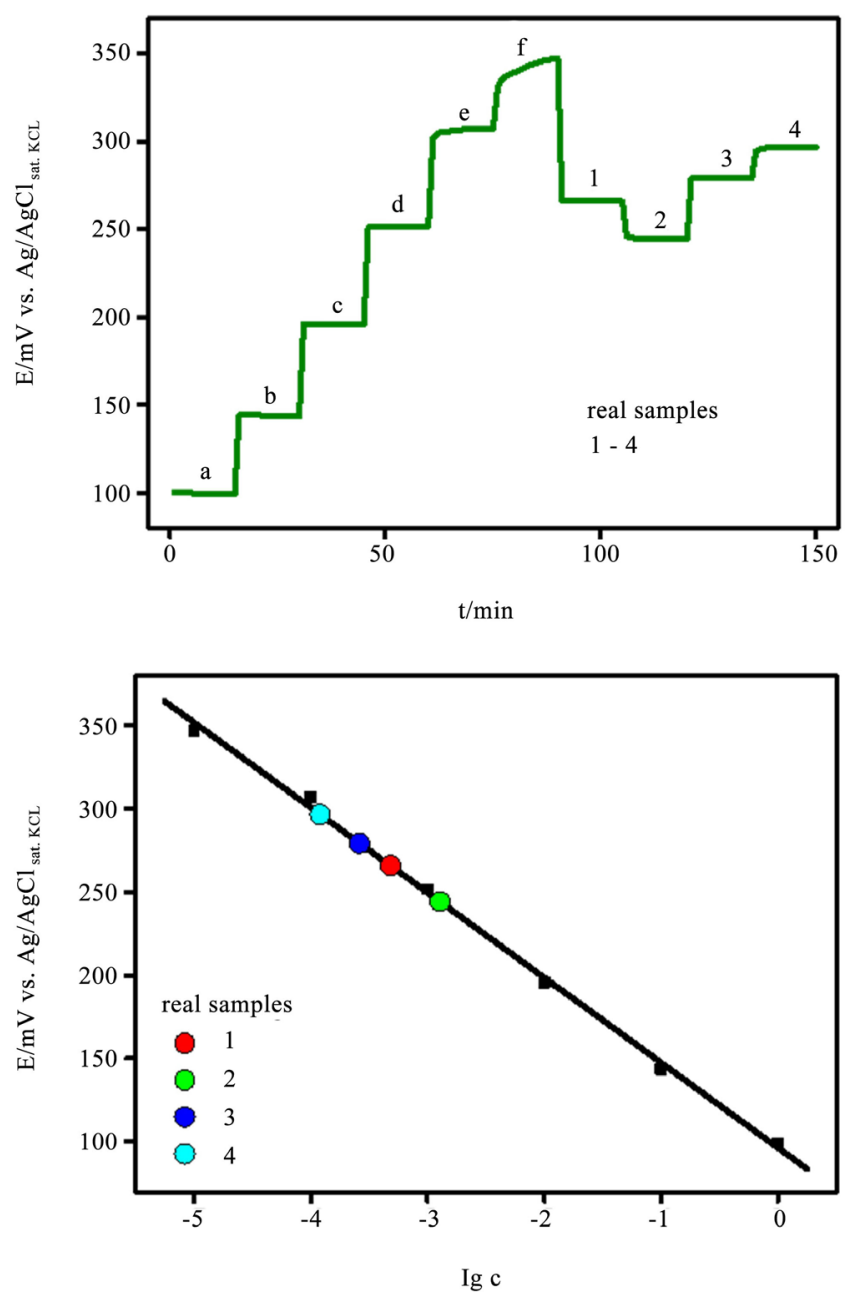

Figure 6. Response behavior and calibration plot of a novel nitrate-selective ASS electrode; standard solutions of $\mathrm{NH}_{4} \mathrm{NO}_{3}$ : a. $1 \mathrm{~mol} / \mathrm{L}$, b. $10^{-1} \mathrm{~mol} / \mathrm{L}, \mathrm{c} .10^{-2} \mathrm{~mol} / \mathrm{L}$, d. $10^{-3} \mathrm{~mol} / \mathrm{L}$, e. $10^{-4} \mathrm{~mol} / \mathrm{L}$, f. $10^{-5} \mathrm{~mol} / \mathrm{L}$; real samples: tap water Enkenbach (1), well water Hermsdorf (2), tap water Köln (3), tap water Leisnig (4).

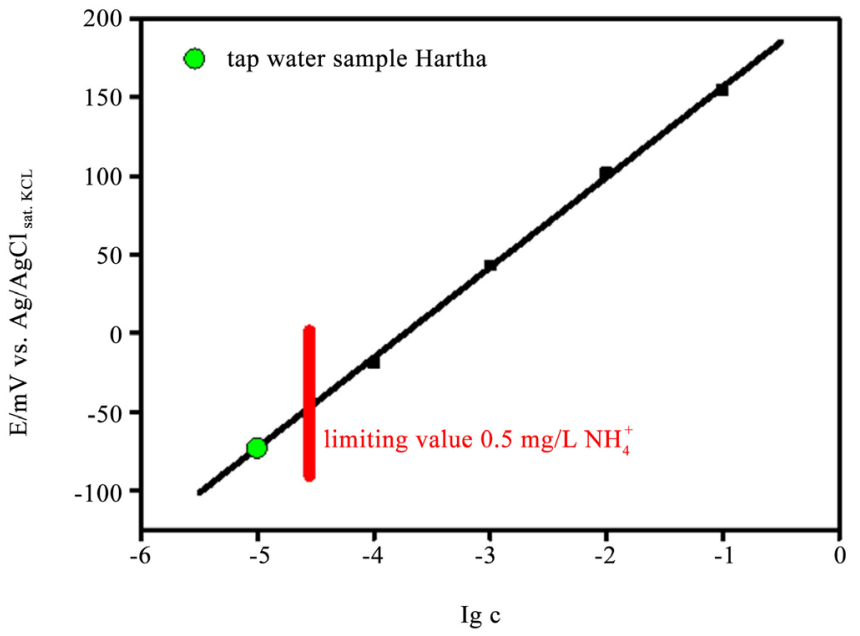

Figure 7. Calibration plot of an ammonium-selective electrode with a tap water sample. 


\section{Conclusion}

Unique liquid-free graphite paste ion-selective ASS electrodes for the detection of ammonium and nitrate ions were developed. The ion-selective electrodes consist of different layers. Polypyrrole has been used as solid contact and intermediate layer between the ion-selective membrane and the solid electron conductor. The solid contact of conducting polymer reduces the irreproducibility and instability of the measured potentials. The ion-selective electrodes show good response behavior and are characterized by easy handling, low cost, long lifetime, as well as by a simple and stable construction form with reproducible functional layers.

\section{Acknowledgements}

The authors are grateful for help in sensor preparation and acknowledge helpful discussions concerning the optimization of the sensor layout by Andreas Klockow, Thomas Kretschmar and Felix Trommer.

\section{Conflicts of Interest}

The authors declare no conflicts of interest regarding the publication of this paper.

\section{References}

[1] Bundesministerium für Umwelt, Naturschutz, Bau und Reaktorsicherheit (2017) Stickstoffeintrag in die Biosphäre. [Nitrogen Entry in the Biosphere.]

[2] Environment Agency Bristol (UK) (2005) Science Report SC030155/SR2, Using Science to Create a Better Place.

[3] Nitratbericht 2016 (Nitrate Report 2016) Bundesministerium für Umwelt, Naturschutz, Bau und Reaktorsicherheit, Bundesministerium für Ernährung und Landwirtschaft.

[4] Deutsche Trinkwasserverordnung (TrinkwV), Verordnung über die Qualität von Wasser für den menschlichen Gebrauch (valid from 09.01.2018).

[5] Artigas, J., Jimenez, C., Lemos, S.G., Nogueira, A.R.A., Torre-Neto, A. and Alonso, J. (2003) Development of a Screen-Printed Thick-Film Nitrate Sensor Based on a Graphite-Epoxy Composite for Agricultural Applications. Sensors and Actuators B, 88, 337-344. https://doi.org/10.1016/S0925-4005(02)00399-4

[6] Faridbod, F., Ganjali, M.R., Dinarvand, R. and Norouzi, P. (2007) The Fabrication of Potentiometric Membrane Sensors and Their Applications. African Journal of Biotechnology, 6, 2960-2987. https://doi.org/10.5897/AJB2007.000-2464

[7] Bomar, E.M., Owens, G.S. and Murray, G.M. (2017) Nitrate Ion Selective Electrode Based on Ion Imprinted Poly(n-methylpyrrole). Chemsensors, 5, 2. https://doi.org/10.3390/chemosensors5010002

[8] Wardak, C. (2014) Solid Contact Nitrate Ion-Selective Electrode Based on Ionic Liquid with Stable and Reproducible Potential. Electroanalysis, 26, 864-872. https://doi.org/10.1002/elan.201300590

[9] Bendikov, T.A., Kim, J. and Harman, T.C. (2005) Development and Environmental Applications of a Nitrate Selective Microsensor Based on Doped Polypyrrole Films. 
Sensors and Actuators B, 106, 512-517. https://doi.org/10.1016/j.snb.2004.07.018

[10] Hassan, S.S.M., Sayour, H.E.M. and Al-Mehrezi, S.S. (2007) A Novel Planar Miniaturized Potentiometric Sensor for Flow Injection Analysis of Nitrates in Wastewaters, Fertilizers and Pharmaceuticals. Analytica Chimica Acta, 581, 13-18. https://doi.org/10.1016/j.aca.2006.08.011

[11] Watts, A.S.., Gavalas, V.G., Cammers, A., Andrada, P.S., Aljarin, M. and Bachas, L.G. (2007) Nitrate-Selective Electrode Based on a Cyclic Bis-Thiourea Ionophore. Sensors and Actuators B, 121, 200-207. https://doi.org/10.1016/j.snb.2006.09.048

[12] Asghari, A., Amini, M.K., Mansour, H.R., Salavati-Niasari, M. and Rajabi, M. (2003) Nitrate-Selective Membrane Electrode Based on Bis(2-hydroxyanil)acetylacetone lead (II) Neutral Carrier. Analytical Sciences, 19, 1121-1125.

https://doi.org/10.2116/analsci.19.1121

[13] Rawat, A., Chandra, S. and Sarkar, A. (2009) Nitrate Selective Polymeric Membrane Electrode Based on Bis-Thiourea Ligand as Carrier. Sensor Letters, 7, 1-6. https://doi.org/10.1166/sl.2009.1242

[14] Schazman, B. and Diamond, D. (2007) Improved Nitrate Sensing Using Ion-Selective Electrodes Based on Urea-Calixarene Ionophores. New Journal of Chemistry, 31, 58-592. https://doi.org/10.1039/B702841P 